\author{
Military Technical College \\ Kobry El-Kobbah, \\ Cairo, Egypt.
}

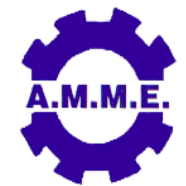

$18^{\text {th }}$ International Conference on Applied Mechanics and Mechanical Engineering.

\title{
THE FAILURE OF LOCAL SHARP-DENTED 6061-T6 ALUMINUM ALLOY TUBES WITH DIFFERENT DIAMETER-TO-THICKNESS RATIOS UNDER CYCLIC BENDING
}

\author{
K. L. Lee ${ }^{1}$, J. T. Lin' ${ }^{2}$ and W. F. Pan ${ }^{3}$
}

\begin{abstract}
In this study, the failure of local sharp-dented 6061-T6 aluminum alloy tubes with different diameter-to-thickness ratios submitted to cyclic bending are investigated. Different diameter-to-thickness ratios of $16.5,31.0$ and 60.0 were considered. The dent depths of tubes were considered from very small to approximately 0.6 times the tube's wall thickness. From the experimental ovalization-curvature relationship, it exhibited an increasing and ratcheting manner when the number of cycles increased. The larger dent depth led to more asymmetrical ovalization-curvature relationship and the greater increase of the ovalization. Furthermore, for a certain diameter-tothickness ratio, five unparallel straight lines corresponding to five different dent depths were found for the controlled curvature-number of cycles required to produce failure relationship on a log-log scale. Finally, a theoretical model was proposed for simulating the aforementioned relationship. Through comparison with the experimental data, the theoretical model can properly simulate the experimental findings.
\end{abstract}

\section{KEY WORDS}

Different Diameter-to-thickness Ratios, Local Sharp-dented 6061-T6 Aluminum Alloy Tubes, Cyclic Bending, Curvature, Ovalization, Number of Cycles Required to Produce Failure.

1 Professor, Dept. of Innovative Design and Entrepreneurship Management, Far East University, Tainan, Taiwan.

2 Graduate student, Dept. of Engineering Science, National Cheng Kung University, Tainan, Taiwan.

3 Professor, Dept. of Engineering Science, National Cheng Kung University, Tainan, Taiwan. 


\section{INTRODUCTION}

It is well known that bending of a circular tube results in ovalization (change in the outer diameter divided by the original outer diameter) of the tube's cross section. This ovalization increases slowly during reverse bending and subsequent cyclic bending, and in turn, results in the degradation of the circular tube, which buckles or fractures when the ovalization reaches a critical value. Circular tubes are severely damaged during buckling and fracturing and cannot bear the load, which ultimately results in obstruction and leakage of the material being transported. As such, a complete understanding of the degradation and failure of circular tubes subjected to cyclic bending is essential for industrial applications.

In 1985, Prof. Kyriakides and his research team designed a bending machine and began a series of experimental and theoretical studies on tubes submitted to monotonic or cyclic bending with or without external or internal pressure. Kyriakides and Shaw [1] then extended the aforementioned research to evaluate the buckling failure of tubes under cyclic bending. Corona and Kyriakides [2] experimentally investigated the behavior of tubes subjected to cyclic bending with external pressure. Vaze and Corona [3] employed a similar bending machine to examine the deterioration and collapse of square steel tubes submitted to cyclic bending. Moreover, Corona and Kyriakides [4] studied the tube's buckling under bending with external pressure. Corona et al. [5] investigated the anisotropy of the plastic deformation for tubes submitted to bending. Limam et al. [6] experimentally and theoretically discussed the inelastic collapse of tubes subjected to bending with internal pressure. Limam et al. [7] also examined the response and collapse of localdented tubes undertaking pure bending with some internal pressure. Bechle and Kyriakides [8] experimentally investigated the localization of NiTi tubes submitted to bending. Jiang et al. [9] studied the pseudoelastic response of NiTi tubes subjected to bending.

In 1998, Pan et al. [10] designed and set up a new measurement apparatus. The apparatus was used with a cyclic bending machine to study various types of tube under different cyclic bending conditions. For examples: Pan and Fan [11] studied the effect of the prior curvature-rate at the preloading stage on subsequent creep or relaxation behavior, and Chang and Pan [12] discussed the buckling life estimation of circular tubes subjected to cyclic bending.

In 2010, the research team of Prof. Pan began to experimentally and theoretically investigate the response and the collapse of sharp-notched circular tubes submitted to cyclic bending. Lee et al. [13] experimentally studied the relationship between the variation of ovalization and the number of bending cycles for sharp-notched circular tubes subjected to cyclic bending. Lee [14] then later investigated the response of sharp-notched SUS304 stainless steel tubes under cyclic bending, and found the asymmetrical, ratcheting, and increasing trends of ovalization-curvature relationships. In addition, Lee et al. [15] evaluated the viscoplastic response and buckling of sharpnotched SUS304 stainless steel circular tubes undertaking cyclic bending. Both the different notch depths and curvature rates were examined. Lee et al. [16] studied the response of sharp-notched circular tubes under pure bending creep and pure bending relaxation Chung et al. [17] investigated the collapse of sharp-notched 6061T6 aluminum alloy tubes subjected to cyclic bending. However, the sharp notch for 
the aforementioned investigations was a circumferential sharp notch as shown in Fig.1.

The investigation of the influence of the $D_{\mathrm{o}} / t$ ratio on the response and failure was first investigated by Lee et al. [18]. The 304 stainless steel smooth tubes with four different $D_{\mathrm{o}} / t$ ratios of $30,40,50$ and 60 were tested under cyclic bending. Later, Chang et al. [19] studied the buckling failure of 301 stainless steel smooth tubes with different $D_{\mathrm{o}} / t$ ratios subjected to cyclic bending. In 2012, Lee et al. [20] started to investigate the influence of the $D_{0} / t$ ratio on the response and failure of sharpnotched 304 stainless tubes subjected to cyclic bending. The type of the sharp notch was in Fig. 1 and three different $D_{\mathrm{o}} / t$ ratios were $16.25,21.20$ and 24.46. They discovered that five almost parallel straight lines corresponding to five different notch depths for each $D_{\mathrm{o}} / t$ ratio were observed from the relationship between the controlled curvature and number of bending cycles required to produce failure on a log-log scale. In addition, the slopes for the aforementioned relationship for three different $D_{\mathrm{o}} / t$ ratios were almost the same.

In this paper, local sharp-dented 6061-T6 aluminum alloy tubes with different $D_{\mathrm{o}} / t$ ratios of $16.5,31.0$ and 60.0 submitted to cyclic bending were experimentally studied. Related experimental tests were conducted by using the tube-bending machine and curvature-ovalization measurement apparatus. The quantities of the curvature and ovalization were measured by sensors on testing facilities. Additionally, the number of bending cycles required to produce failure was also recorded

\section{EXPERIMENTS}

A tube-bending machine and a curvature-ovalization measurement apparatus were used to conduct the cyclic bending test on local sharp-dented 6061-T6 aluminum alloy tubes with different $D_{\mathrm{o}} / t$ ratios. The details on the experimental device, materials, specimens, and test procedures were presented in the sections that follow.

\section{Experimental Device}

Figure $2 \mathrm{a}$ schematically shows the experiments executed by a specially built tubebending machine. This facility was built to conduct monotonic, reverse, and cyclic bending tests. A detailed explanation of the experimental facility can be found in many papers (Pan et al. [10], Pan and Fan [11]). Pan et al. [10] designed a new lightweight apparatus to measure the curvature and the ovalization of the tube's cross section shown in Fig. 2b. Two side-inclinometers in the apparatus were used to detect the tube's angle variation during cyclic bending. The tube curvature can be determined by a simple calculation according to the angle changes. An extended version of the calculation can be found in the work by Pan et al. [10]. In addition, the tube ovalization can be measured in the center part of the apparatus that included a magnetic detector and a magnetic block.

\section{Material and Specimens}

6061-T6 aluminum alloy tubes were used for the experimental testing. Table 1 lists the chemical composition (weight \%) of the tested material. The mechanical 
properties were $0.2 \%$ offset yield stress $\left(\sigma_{\mathrm{o}}\right)=166 \mathrm{MPa}$, ultimate stress $\left(\sigma_{\mathrm{u}}\right)=258$ $\mathrm{MPa}$, and percent elongation $\left(100 \varepsilon_{\mathrm{f}}\right)=23 \%$.

The raw, smooth 6061-T6 aluminum alloy circular tubes had a length $L_{0}$ of $800 \mathrm{~mm}$, an outer diameter $D_{\mathrm{o}}$ of $35.0 \mathrm{~mm}$ and a wall thickness $t$ of $3.0 \mathrm{~mm}$. The raw tubes were machined on the outside surface to obtain the desired $D_{\mathrm{o}} / t$ ratios of $16.5,31.0$ and 60.0 as shown in Fig. 3. Next, tubes with a certain $D_{\mathrm{o}} / t$ ratio were processed on the outside surface again to obtain the desired shape and depth of the dent $(a)$. Figs. $4 \mathrm{a}$ and $4 \mathrm{~b}$ show a picture and a schematic drawing of processing a dent on the 6061T6 aluminum alloy tube, respectively. The upper mould contacted the 6061-T6 aluminum alloy tube's surface and exerted a pressure $\mathrm{F}$ to create a dent. In this study, five different depth-to-thickness $(a / t)$ ratios were considered: $0.0,0.15,0.3$, 0.45 , and 0.6 . Note that $a / t=0.0$ represents a tube with a smooth surface. It can be seen from Fig. 3 that the magnitudes of $t$ for $D_{\mathrm{o}} / t$ ratios of $16.5,31.0$ and 60.0 are 2.0, 1.0 and $0.5 \mathrm{~mm}$, respectively. Therefore, the magnitudes of $a$ for $D_{\mathrm{o}} / t=16.5$ are 0.0 , $0.3,0.6,0.9$ and $1.2 \mathrm{~mm}$. The magnitudes of $a$ for $D_{\mathrm{o}} / t=31.0$ are $0.0,0.15,0.3,0.45$, and $0.6 \mathrm{~mm}$ and the magnitudes of $a$ for $D_{\mathrm{o}} / t=60.0$ are $0.0,0.075,0.15,0.225$, and $0.3 \mathrm{~mm}$. Figure 5 shows a picture of local sharp-dented 6061-T6 aluminum alloy tubes with $D_{\mathrm{o}} / t=16.5$ and $a=0.0,0.3,0.6,0.9$ and $1.2 \mathrm{~mm}$.

\section{Test Procedures}

The test involved a curvature-controlled cyclic bending. The controlled-curvature ranges were from \pm 0.2 to $\pm 1.1 \mathrm{~m}^{-1}$, and the curvature rate of the cyclic bending test was $0.035 \mathrm{~m}^{-1} \mathrm{~s}^{-1}$. The magnitude of the curvature and ovalization of the tube's cross section were controlled and measured by the curvature-ovalization measurement apparatus. In addition, the number of cycles required to produce failure was recorded.

\section{EXPERIMENT RESULTS AND DISCUSSION}

\section{Mechanical Response}

The experimental ovalization $\left(\Delta D_{0} / D_{0}\right)$ - curvature $(\kappa)$ relationships for local sharpdented 6061-T6 aluminum alloy tubes with $D_{\mathrm{o}} / t=16.5$ and $a=0.0,0.3,0.6,0.9$, and $1.2 \mathrm{~mm}$ subjected to cyclic bending are shown in Figs. $6 a$ to $6 \mathrm{e}$, respectively. The tubes were cycled between curvatures of $\pm 0.4 \mathrm{~m}^{-1}$. It is noted that the $\Delta D_{\mathrm{o}} / D_{\mathrm{o}}-\kappa$ curves exhibit a ratcheting trend and increase with the number of bending cycles. $A$ larger $a$ leads to a more asymmetrical look to the $\Delta D_{\mathrm{o}} / D_{\mathrm{o}}-\kappa$ curve. Moreover, a larger $a$ leads to a larger ovalization.

The ovalization $\left(\Delta D_{\mathrm{o}} / D_{\mathrm{o}}\right)$ - curvature $(\kappa)$ relationships for local sharp-dented 6061-T6 aluminum alloy tubes with $D_{\mathrm{o}} / t=31.0$ and $a=0.0,0.15,0.3,0.45$, and $0.6 \mathrm{~mm}$ subjected to cyclic bending are shown in Figs. 7a to 7e, respectively. The ovalization $\left(\Delta D_{\mathrm{o}} / D_{\mathrm{o}}\right)$ - curvature $(\kappa)$ relationships for local sharp-dented 6061-T6 aluminum alloy tubes with $D_{\mathrm{o}} / t=60.0$ and $a=0.0,0.075,0.15,0.225$, and $0.3 \mathrm{~mm}$ subjected to cyclic bending are shown in Figs. $8 \mathrm{a}$ to $8 \mathrm{e}$, respectively. The tubes were also cycled between curvatures of $\pm 0.4 \mathrm{~m}^{-1}$. It is demonstrated that the $\Delta D_{\mathrm{o}} / D_{\mathrm{o}}-\kappa$ curves also 
exhibit a ratcheting trend and increase with the number of bending cycles. A larger $a$ also leads to a more asymmetrical appearance of the $\Delta D_{0} / D_{0}-\kappa$ curve and a larger ovalization. In addition, for a constant $a$ of $0.3 \mathrm{~mm}$ in Fig. 6b, Fig. 7c and Fig. 8e, a larger $D_{\mathrm{o}} / t$ ratio leads to a larger ovalization.

\section{Failure}

Figures $9 \mathrm{a}$ to $9 \mathrm{c}$ present the experimental data of the cyclic controlled curvature $\left(\kappa_{\mathrm{c}} / \kappa_{\mathrm{o}}\right)$ versus the number of cycles required to produce failure $\left(N_{\mathrm{f}}\right)$ for local sharpdented 6061-T6 aluminum alloy tubes with $D_{\mathrm{o}} / t=16.5,31.0$ and 60.0, respectively, subjected to cyclic bending. The controlled curvature was normalized by $\kappa_{0}=t / D_{0}{ }^{2}[2]$. For a certain $\kappa_{\mathrm{c}} / \kappa_{\mathrm{o}}$ and $a$, tubes with a larger $D_{\mathrm{o}} / t$ ratios led to a lower $N_{\mathrm{f}}$. In addition, for a certain $D_{\mathrm{o}} / t$ ratio and $\kappa_{\mathrm{c}} / \kappa_{0}$, tubes with a larger $a$ led to a lower $N_{\mathrm{f}}$. Subsequently, the experimental data in Figs. 9a to 9c were plotted on a log-log scale, and five straight dot lines were observed in Figs.10a to 10c. Note that the dot lines were determined by the least square method. It can be seen that five unparallel dot lines corresponding to five different $a$ for each $D_{\mathrm{o}} / t$ ratio.

In 1987, Kyriakides and Shaw [2] proposed an empirical formulation to describe the relationship between $\kappa_{\mathrm{c}} / \kappa_{0}$ and $N_{\mathrm{f}}$ to be:

$$
\kappa_{\mathrm{c}} / \kappa_{\mathrm{o}}=C\left(N_{\mathrm{f}}\right)^{-\alpha}
$$

or

$$
\log \kappa_{\mathrm{c}} / \kappa_{\mathrm{o}}=\log C-\alpha \log N_{\mathrm{f}}
$$

where $C$ and $\alpha$ are the material parameters, which are related to the material and $D_{0} / t$ ratios. The parameter $C$ is the amount of $\kappa_{\mathrm{c}} / \kappa_{\mathrm{o}}$ when $N_{\mathrm{f}}=1$, and the parameter $\alpha$ is the slope of the log-log plot. The formulation has been successfully simulated the $\kappa_{\mathrm{c}} / \kappa_{0}-N_{\mathrm{f}}$ relationships for 6061-T6 aluminum alloy and 1018 carbon steel smooth tubes subjected to cyclic bending [2].

In this study, the liner relationships between $C^{0.25}$ and $(a / t)^{0.5}$ and $\alpha^{0.25}$ and a/t were found in Figs.11a and 11b, respectively. Therefore, we write

$$
C^{0.25}=C_{0}-\beta\left(\frac{a}{t}\right)^{0.5}, \quad a \geq 0
$$

and

$$
\alpha^{0.25}=\alpha_{0}-\gamma\left(\frac{a}{t}\right), \quad a \geq 0
$$

where $C_{0}, \beta, \alpha_{0}$ and $\gamma$ are material parameters. The magnitudes of $C_{0}, \beta, \alpha_{0}$ and $\gamma$ can be determined for each $D_{\mathrm{o}} / t$ from Figs.11a and 11b.

Next, the material parameters $C_{0}, \beta, \alpha_{0}$ and $\gamma$ were assumed to be related to $D_{\mathrm{o}} / t$ ratios. In this study, we tried to find the linear relationships of the above material 
parameters with $D_{\mathrm{o}} / t$ ratios. After a lot of attempts, the linear relationships were obtained in Figs.12a to $12 \mathrm{~d}$. Thus, the linear relationships can be written to be:

$$
\begin{aligned}
& C_{\mathrm{o}}^{0.25}=f_{1}\left(D_{\mathrm{o}} / t\right)+f_{2} \\
& \beta^{0.25}=g_{1}\left(D_{\mathrm{o}} / t\right)^{0.5} g_{2} \\
& \alpha_{\mathrm{o}}^{0.25}=h_{1}\left(D_{\mathrm{o}} / t\right)+h_{2}
\end{aligned}
$$

and

$$
\gamma^{0.25}=i_{1}\left[\frac{1}{\ln \left(D_{\mathrm{o}} / t\right)}\right]^{2}+i_{2}
$$

where $f_{1}, f_{2}, g_{1}, g_{2}, h_{1}, h_{2}, i_{1}$ and $i_{2}$ are material constants. These material constants can be determined form the intercept and slope of each line in Figs.12a to $12 \mathrm{~d}$ to be $0.004,1.133,-1.05,1.2347,-0.0044,0.7987,4.6538$ and 0.1012 , respectively. Finally, Eqns. (2) to (8) were used to simulate the experimental data in Figs.10a to 10c. The simulated results of the relationship between the controlled curvature $\left(\kappa_{\mathrm{c}} / \kappa_{\mathrm{o}}\right)$ and number of bending cycles required to produce failure $\left(N_{\mathrm{f}}\right)$ curves for local sharpdented 6061-T6 aluminum alloy tubes with $D_{\mathrm{o}} / t=16.5,31.0$ and 60.0 , respectively, subjected to cyclic bending on a log-log scale are depict in Figs.10a to 10c in solid lines. Good agreement between the experimental and simulated results has been achieved.

\section{CONCLUSIONS}

This study investigated the failure of local sharp-dented 6061-T6 aluminum alloy tubes with different $D_{\mathrm{o}} / t$ ratios submitted to cyclic bending. Some important conclusions are sorted as follows according to the experimental and simulated results:

(1) The experimental $\Delta D_{\mathrm{o}} / D_{\mathrm{o}}-\kappa$ relationship for local sharp-dented 6061-T6 aluminum alloy tubes with any $D_{\mathrm{o}} / t$ ratio or $a$ revealed an increasing and ratcheting trend with the number of bending cycles. The $\Delta D_{\mathrm{o}} / D_{\mathrm{0}}-\kappa$ relationships were symmetrical for $a=0.0 \mathrm{~mm}$, but asymmetrical for $a \neq 0.0 \mathrm{~mm}$. In addition, the tubes with a larger $D_{\mathrm{o}} / t$ or $a$ led to more asymmetrical trend and a larger ovalization.

(2) From the experimental $\kappa_{\mathrm{c}} / \kappa_{\mathrm{o}}$ and $N_{\mathrm{f}}$ relationships, for a certain $\kappa_{\mathrm{c}} / \kappa_{\mathrm{o}}$ and $a$, tubes with a larger $D_{\mathrm{o}} / t$ ratios led to a lower $N_{\mathrm{f}}$. In addition, for a certain $D_{\mathrm{o}} / t$ ratio and $\kappa_{\mathrm{c}} / \kappa_{0}$, tubes with a larger $a$ led to a lower $N_{\mathrm{f}}$. From the experimental $\kappa_{\mathrm{c}} / \kappa_{\mathrm{o}}$ and $N_{\mathrm{f}}$ relationships on a log-log scale, five straight lines determined by least square method were found. It can be seen that five unparallel lines corresponding to five different $a$ for each $D_{\mathrm{o}} / t$ ratio.

(3) The empirical formulation of Eqn.(2) proposed by Kyriakides and Shaw [2] was modified to simulate the $\kappa_{\mathrm{c}} / \kappa_{\mathrm{o}}-N_{\mathrm{f}}$ relationship for local sharp-dented 6061-T6 aluminum alloy tubes with different $D_{\mathrm{o}} / t$ ratios submitted to cyclic bending. According to the experimental data, the forms of the material parameters, $C$ and $\alpha$, were proposed in Eqn.(3) and Eq.n(4), respectively. In addition, The forms of the material parameters, $C_{0}, \beta, \alpha_{0}$ and $\gamma$, were proposed in Eqns.(5) to (8), 
respectively. The results simulated by Eqns. (2) to (8) were in good agreement with the experimental findings (Figs.10a to 10c)

\section{ACKNOWLEDGEMENT}

The work presented was carried out with the support of the Ministry of Science and Technology under grant MOST 105-2221-E-006-073. Its support is gratefully acknowledged.

\section{REFERENCES}

[1] S. Kyriakides and P.K. Shaw, "Inelastic Buckling of Tubes under Cyclic Loads", ASME J. Pre. Ves. Tech., Vol. 109, No. 2, pp. 169-178 (1987).

[2] E. Corona and S. Kyriakides, "An Experimental Investigation of the Degradation and Buckling of Circular Tubes under Cyclic Bending and External Pressure", Thin-Walled Struct., Vol. 12, No. 3, pp. 229-263 (1991).

[3] S. Vaze and E. Corona, "Degradation and Collapse of Square Tubes under Cyclic Bending", Thin-Walled Struct., Vol. 31, No. 4, pp. 325-341 (1998).

[4] E. Corona and S. Kyriakides, "Asymmetric Collapse Modes of Pipes under Combined Bending and External Pressure", J. Eng. Mech., Vol. 126, No. 12, pp. 1232-1239 (2000).

[5] E. Corona, L.H. Lee and S. Kyriakides, "Yield Anisotropic Effects on Buckling of Circular Tubes under Bending", Int. J. Solids Struct., Vol. 43, No. 22, pp. 7099-7118 (2006).

[6] A. Limam, L.H. Lee, E. Corana and S. Kyriakides, "Inelastic Wrinkling and Collapse of Tubes under Combined Bending and Internal Pressure", Int. J. Mech. Sci., Vol. 52, No. 5, pp. 637-647 (2010).

[7] A. Limam, L.H. Lee and S. Kyriakides, "On the Collapse of Dented Tubes under Combined Bending and Internal Pressure", Int. J. Mech. Sci., Vol. 55, No. 1, pp. 1-12 (2012).

[8] N.J. Bechle and S. Kyriakides, "Localization of NiTi Tubes under Bending", Int. J. Solids Struct., Vol. 51, No. 5, pp. 967-980 (2014).

[9] D. Jiang, S. Kyriakides, N.J. Bechle and C. M. Landis, "Bending of Pseudoelastic NiTi Tubes", Int. J. Solids Struct., Vol. 124, pp. 192-214 (2017).

[10] W.F. Pan, T.R. Wang and C.M. Hsu, "A Curvature-ovalization Measurement Apparatus for Circular Tubes under Cyclic Bending", Exp. Mech., Vol. 38, No. 2, pp. 99-102 (1998).

[11] W.F. Pan and C.H. Fan, "An Experimental Study on the Effect of Curvaturerate at Preloading Stage on Subsequent Creep or Relaxation of Thin-walled Tubes under Pure bending", JSME Int. J., Series A, Vol. 41, No. 4, pp. 525-531 (1998).

[12] K.H. Chang and W.F. Pan, "Buckling Life Estimation of Circular Tubes under Cyclic Bending", Int. J. Solids Struct., Vol. 46, No. 2, pp. 254-270 (2009).

[13] K.L. Lee, C.Y. Hung and W.F. Pan, "Variation of Ovalization for Sharp-notched Circular Tubes under Cyclic Bending”, J. Mech., Vol. 26, No. 3, pp. 403-411 (2010).

[14] K.L. Lee, "Mechanical Behavior and Buckling Failure of Sharp-notched Circular Tubes under Cyclic Bending", Struct. Eng. Mech., Vol. 34, No. 3, pp. 367-376 (2010). 
[15] K.L. Lee, C.M. Hsu and W.F. Pan, "Viscoplastic Collapse of Sharp-notched Circular Tubes under Cyclic Bending", Acta Mech. Solida Sinica, Vol. 22, No. 6, pp. 629-641 (2013).

[16] K.L. Lee, C.M. Hsu and W.F. Pan, "Response of Sharp-notched Circular Tubes under Bending Creep and Relaxation", Mech. Eng. J., Vol. 1, No. 2, pp. 1-14 (2014).

[17] C.C. Chung, K.L. Lee and W.F. Pan, "Collapse of Sharp-Notched 6061-T6 Aluminum Alloy Tubes Under Cyclic Bending", Int. J. Struct. Stab. Dyn., Vol. 16, No. 7, 1550035 (24 pages) (2016).

[18] K.L. Lee, W.F. Pan and J.N. Kuo, "The Influence of the Diameter-to-thickness Ratio on the Stability of Circular Tubes under Cyclic Bending", Int. J. Solids Struct., Vol. 38, No. 14, pp. 2401-2413 (2001).

[19] K.H. Chang, K.L. Lee and W.F. Pan, "Buckling Failure of 310 Stainless Steel Tubes with Different Diameter-to-thickness Ratios under Cyclic Bending", Steel Comp. Struct., Vol. 10, No. 3, pp. 224-245 (2010).

[20] K.L. Lee, C.M. Hsu and W.F. Pan, "The Influence of the Diameter-to-thickness Ratio on the Response and Collapse of Sharp-notched Circular Tubes under Cyclic Bending", J. Mech., Vol. 28, No. 3, pp. 461-468 (2012).

\section{Figures and Table}

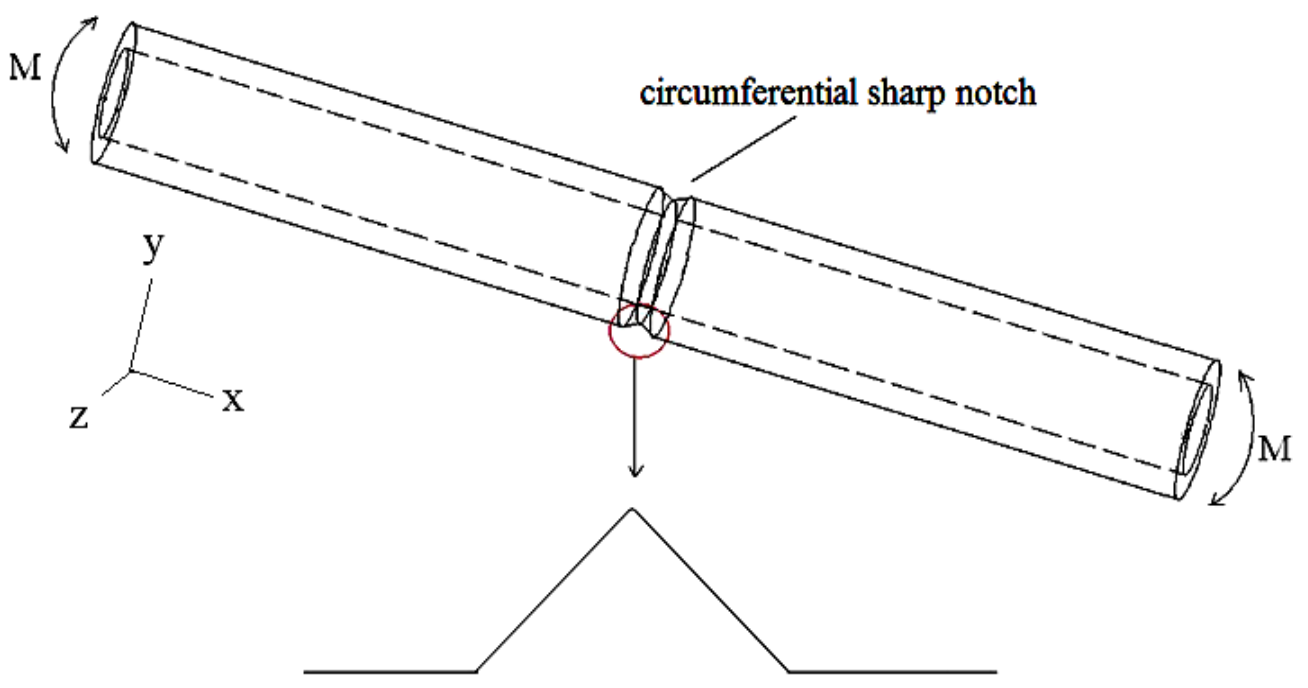

Fig.1. Schematic drawing of the circumferential sharp-notched tube. 


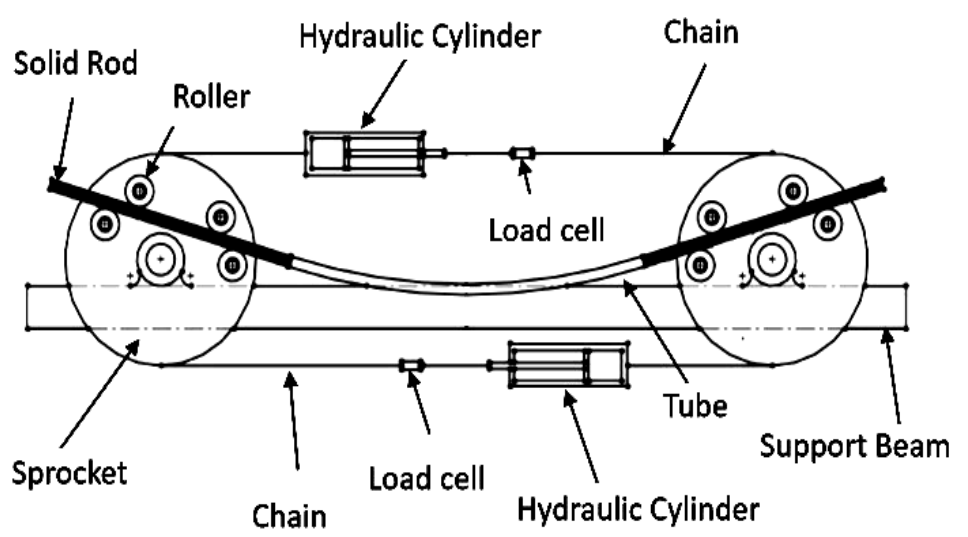

(a)

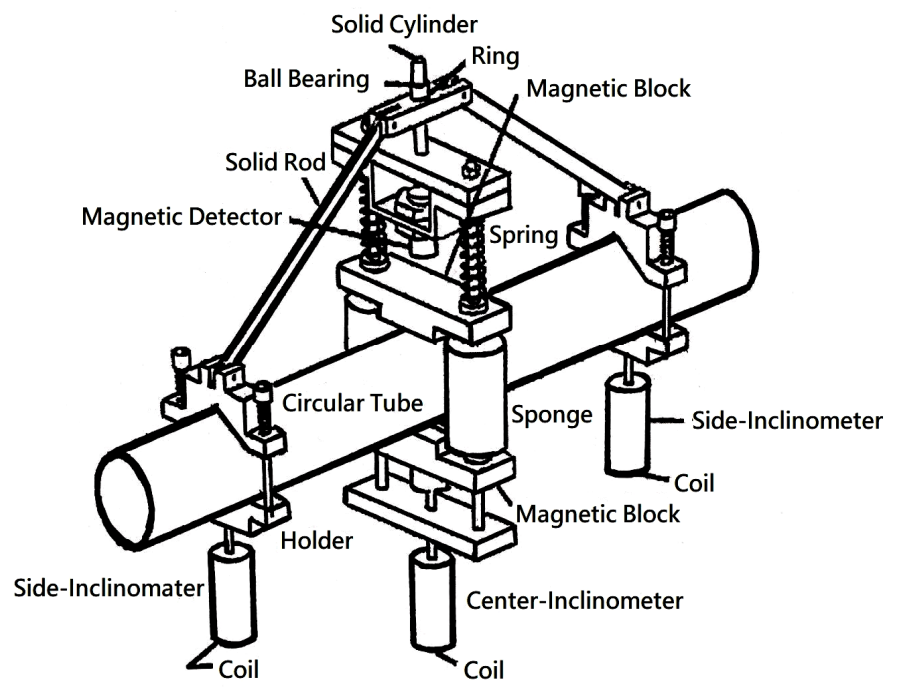

(b)

Fig. 2. (a) Schematic drawing of the tube-bending machine, and (b) schematic drawing of the curvature-ovalization measurement apparatus.
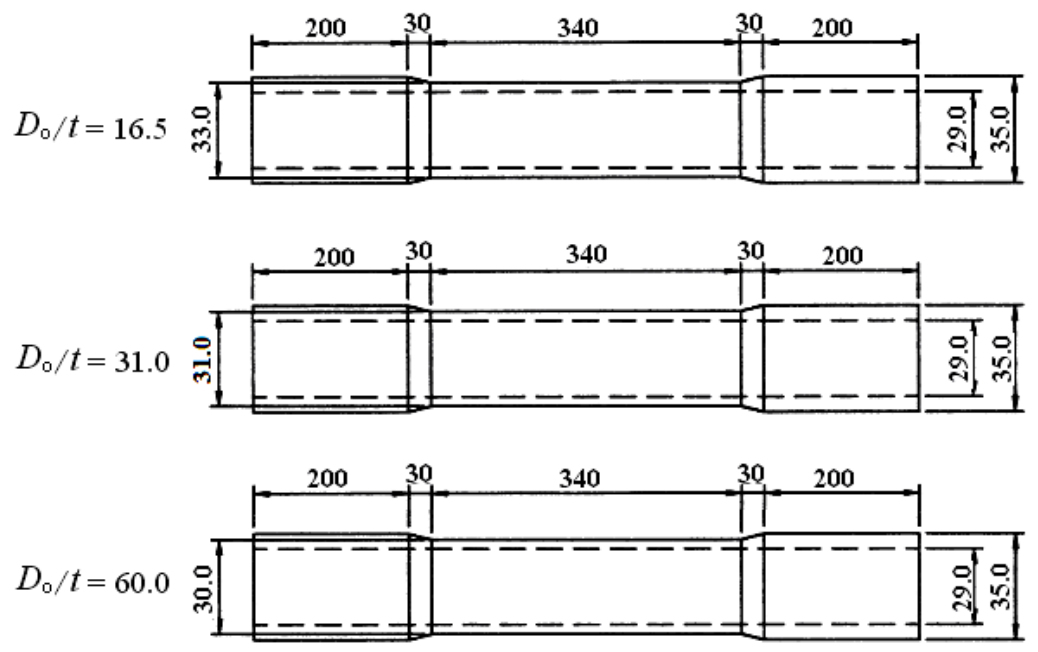

Fig. 3. Schematic drawing of tube's dimensions for $D_{\mathrm{o}} / t$ ratios of $16.5,31.0$ and 60.0. 


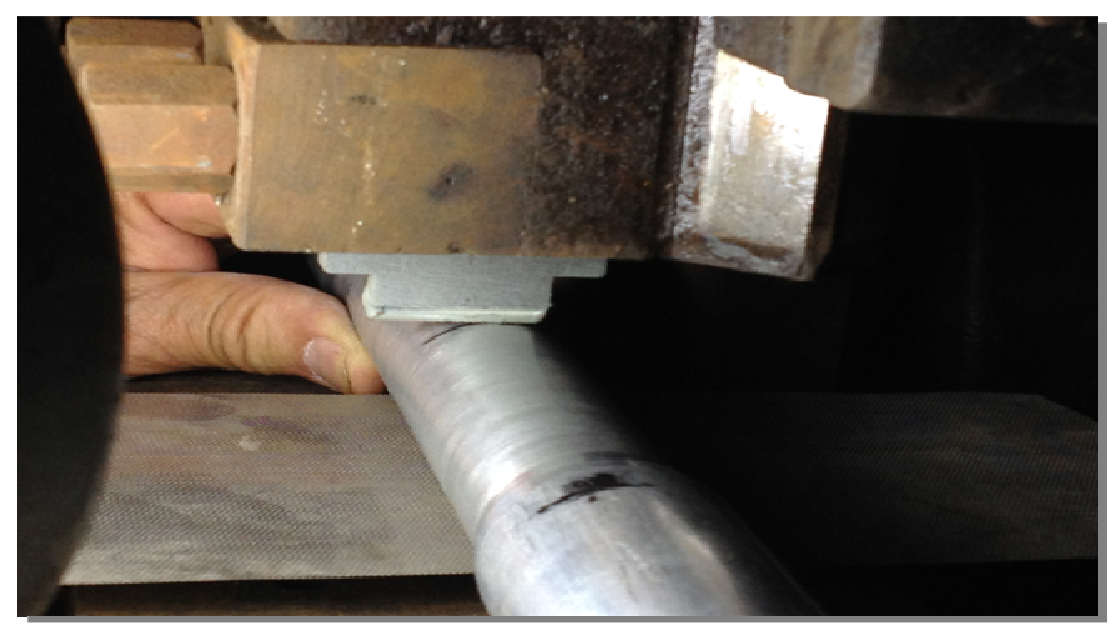

(a)

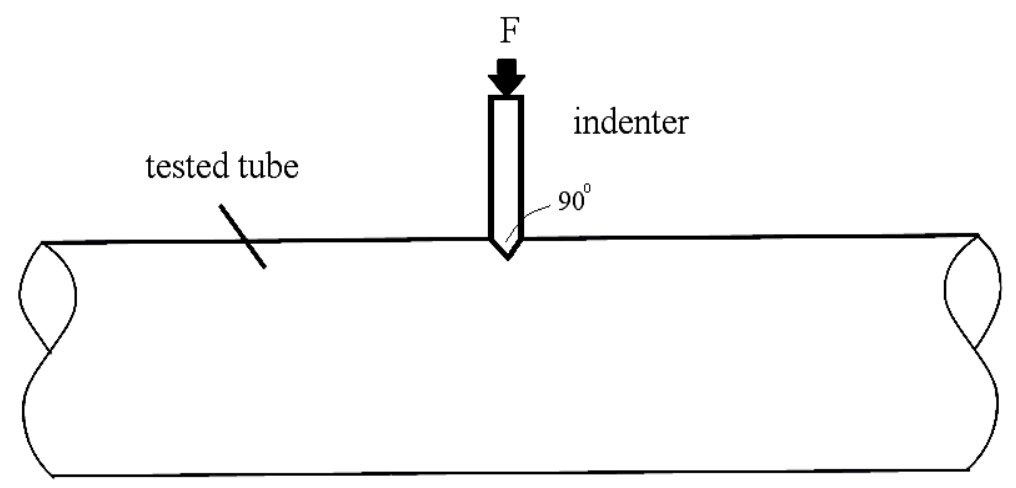

(b)

Fig. 4. (a) Picture of processing a sharp dent on the 6061-T6 aluminum alloy tube, and (b) schematic drawing of processing a sharp dent on the 6061-T6 aluminum alloy tube.

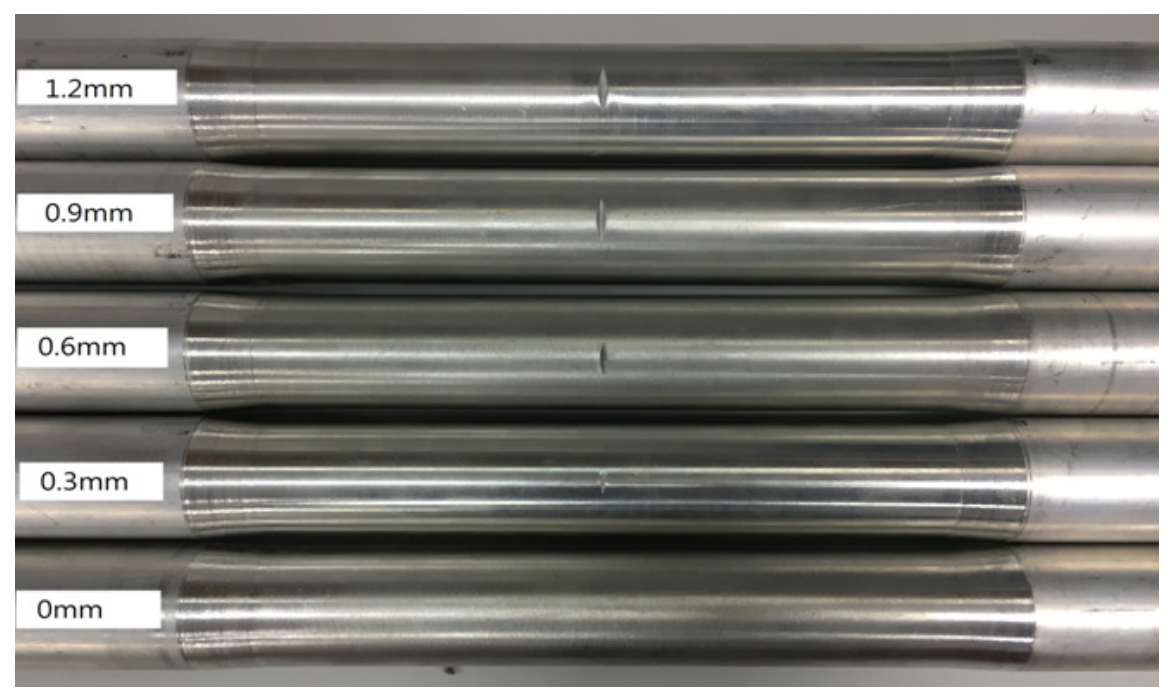

Fig. 5. Picture of local sharp-dented 6061-T6 aluminum alloy tubes with $D_{\mathrm{o}} / t=16.5$ and $a=0.0,0.3,0.6,0.9$ and $1.2 \mathrm{~mm}$. 


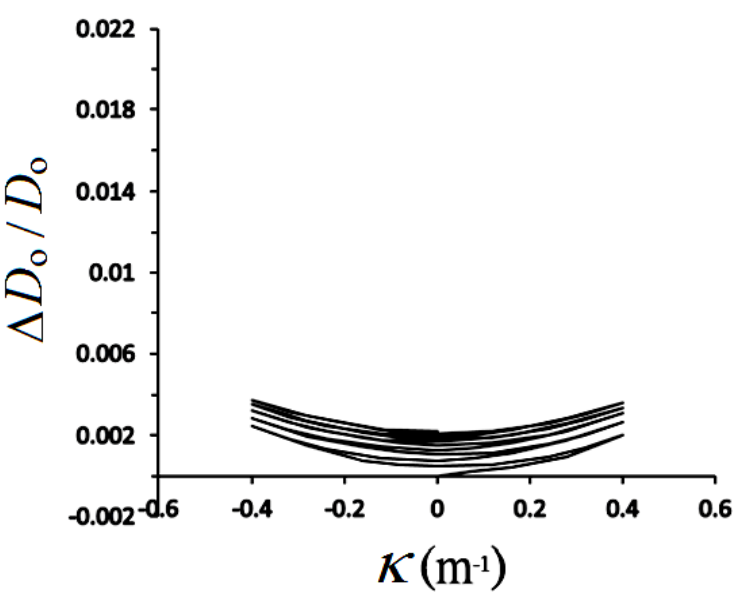

(a)

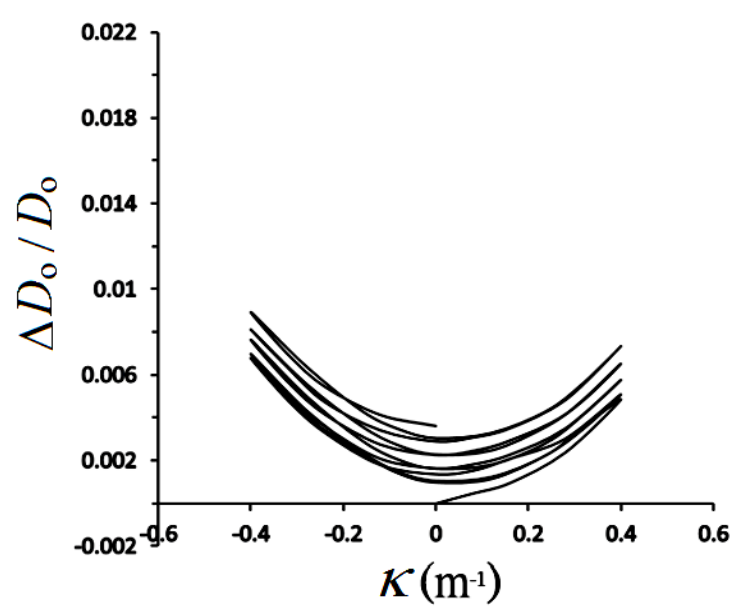

(c)

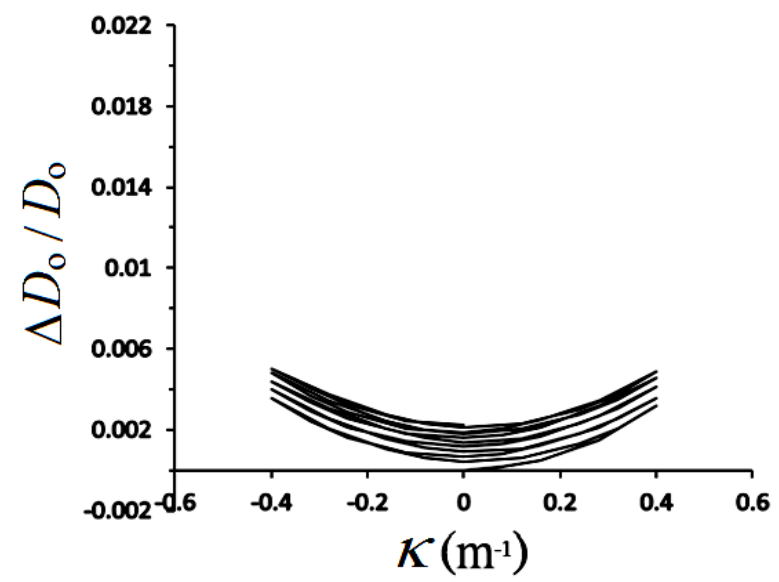

(b)

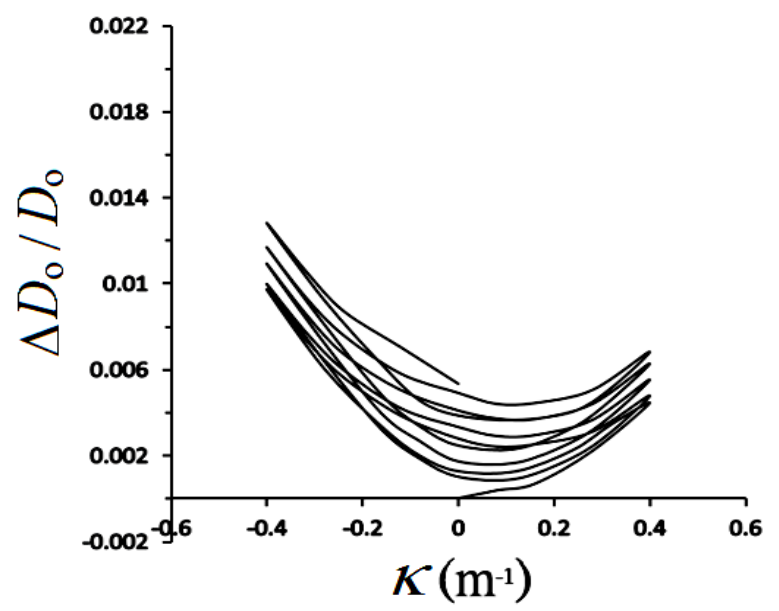

(d)

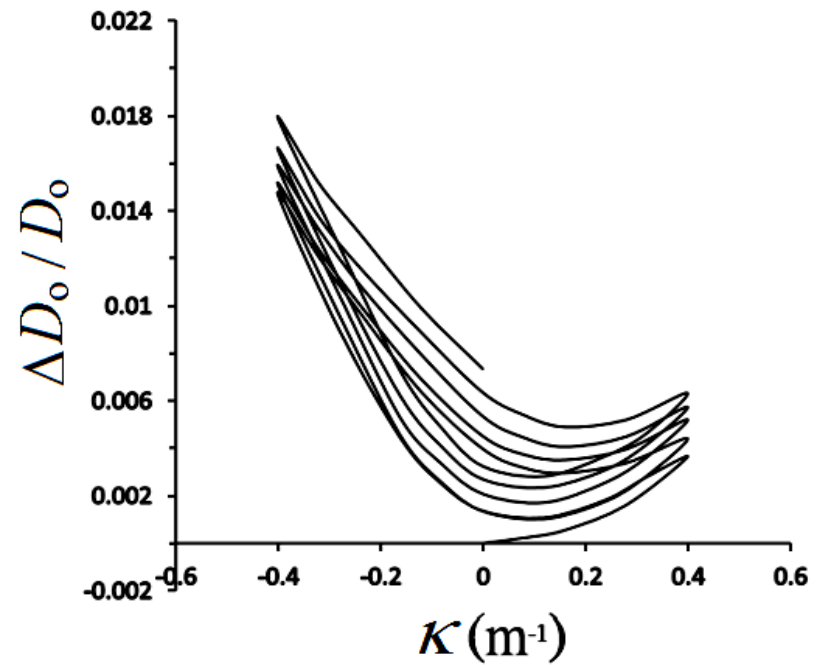

(e)

Fig. 6. Experimental ovalization $\left(\Delta D_{\mathrm{o}} / D_{\mathrm{o}}\right)$ - curvature $(\kappa)$ curves for local sharp-dented 6061-T6 aluminum alloy tubes with $D_{\mathrm{o}} / t=16.5$ and $a=$ (a) 0.0 , (b) 0.3 , (c) 0.6, (d) 0.9 and (e) $1.2 \mathrm{~mm}$ subjected to cyclic bending. 


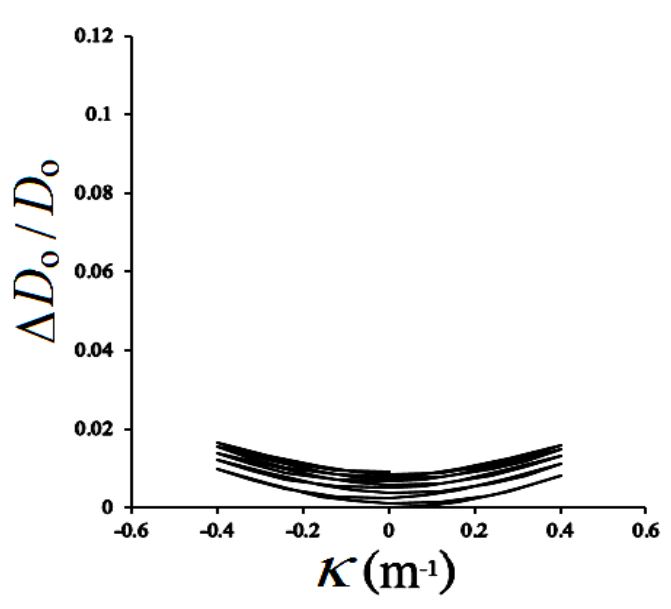

(a)

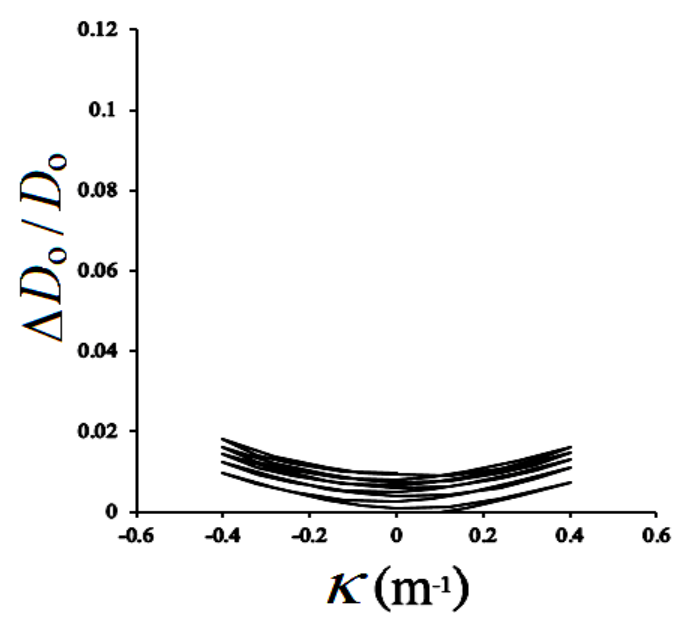

(c)

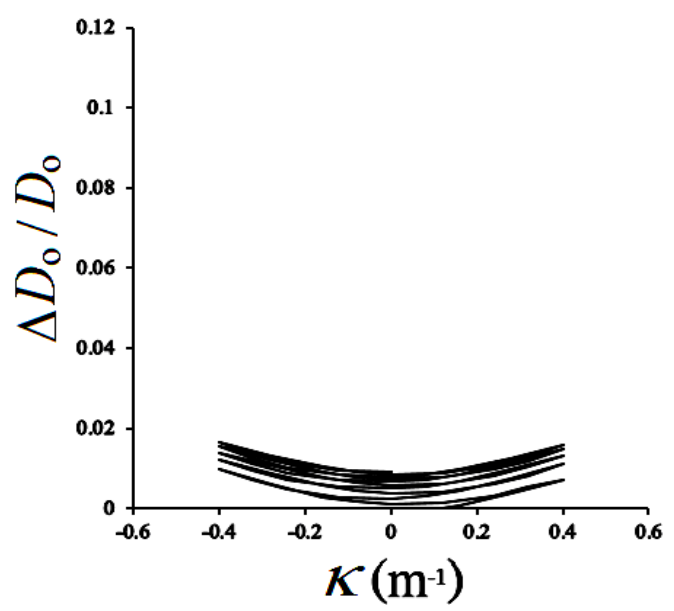

(b)

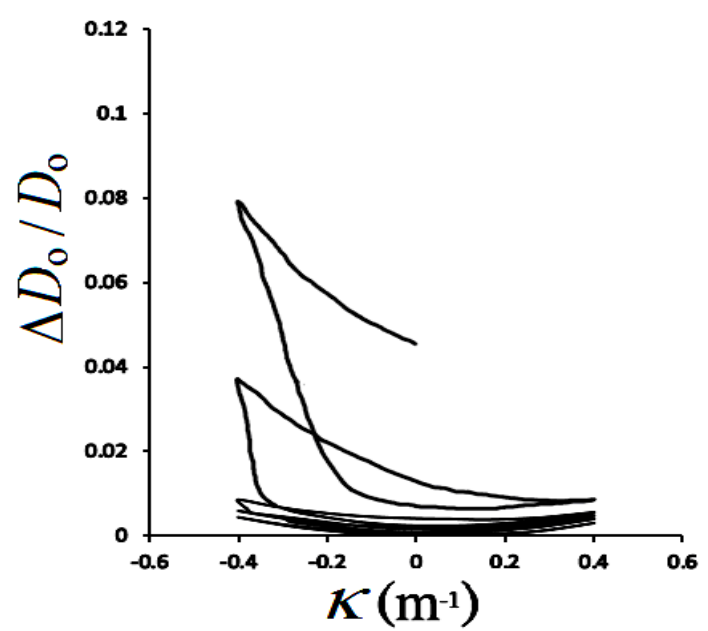

(d)

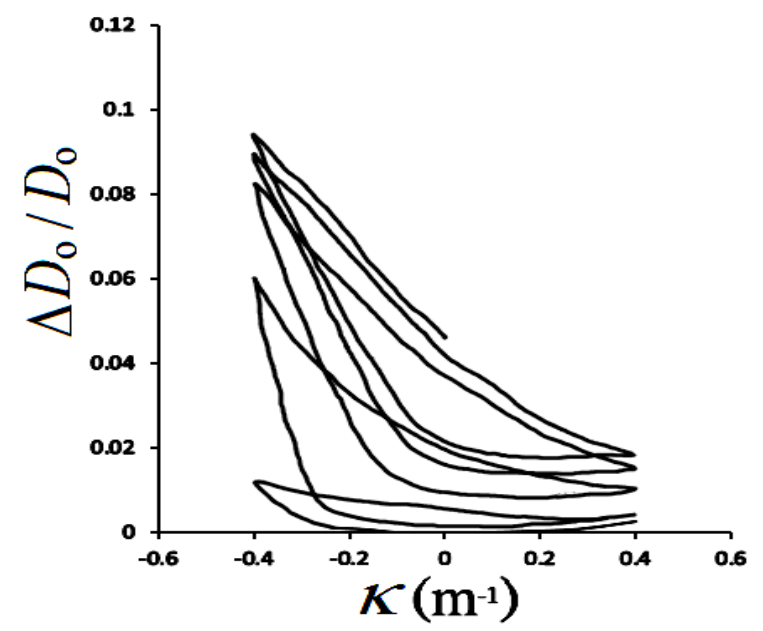

(e)

Fig.7. Experimental ovalization $\left(\Delta D_{\mathrm{o}} / D_{\mathrm{o}}\right)$ - curvature $(\kappa)$ curves for local sharp-dented 6061-T6 aluminum alloy tubes with $D_{\mathrm{o}} / t=31.0$ and $a=$ (a) 0.0 , (b) 0.15 , (c) 0.3 , (d) 0.45 and (e) $0.6 \mathrm{~mm}$ subjected to cyclic bending. 


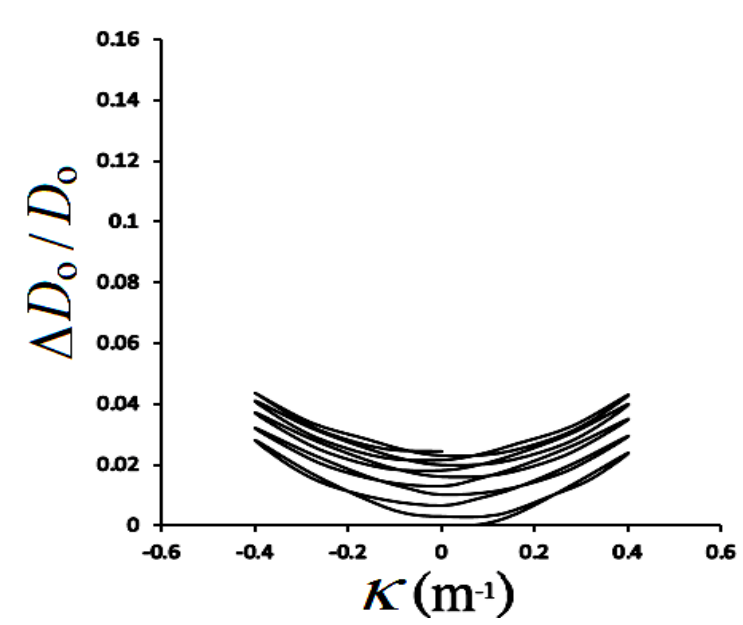

(a)

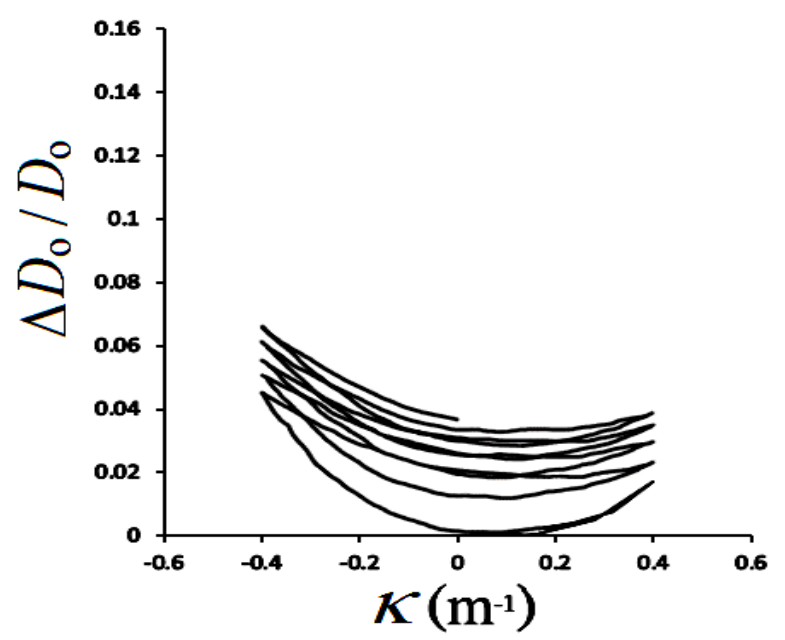

(c)

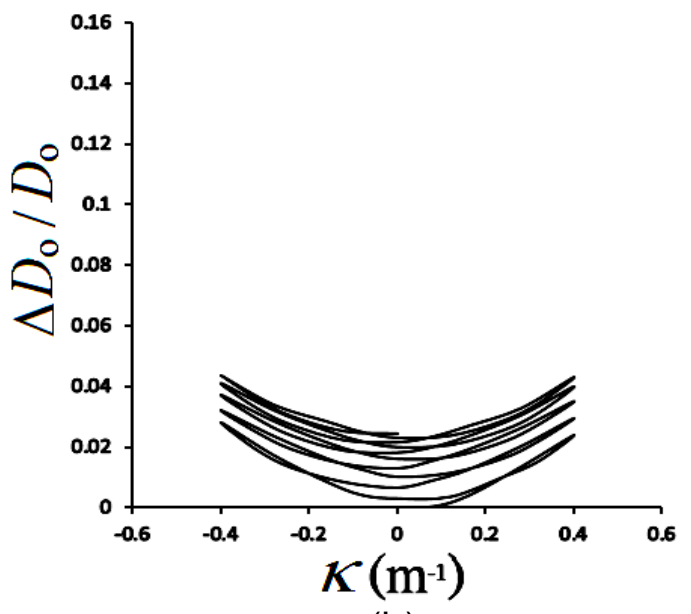

(b)

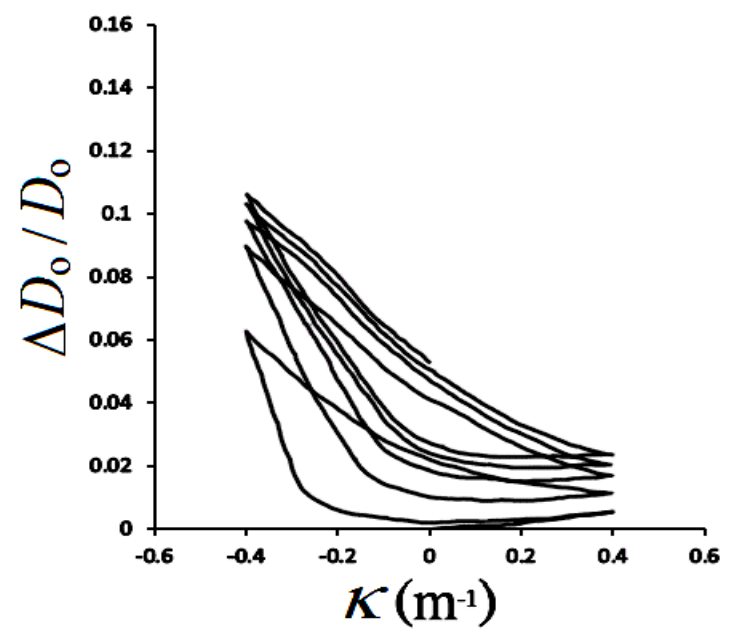

(d)

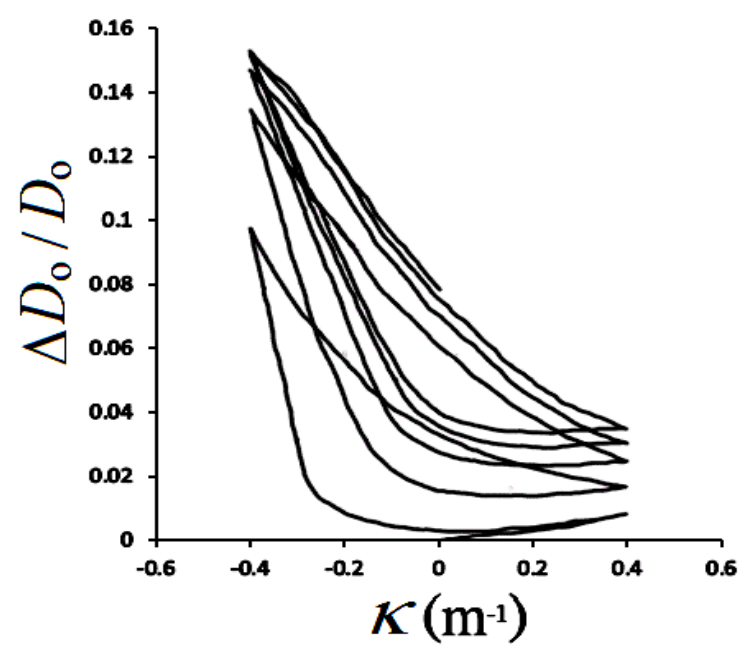

(e)

Fig. 8. Experimental ovalization $\left(\Delta D_{\mathrm{o}} / D_{\mathrm{o}}\right)$ - curvature $(\kappa)$ curves for local sharp-dented 6061-T6 aluminum alloy tubes with $D_{\mathrm{o}} / t=60.0$ and $a=$ (a) 0.0 , (b) 0.075 , (c) 0.15 , (d) 0.225 and (e) $0.3 \mathrm{~mm}$ under cyclic bending. 


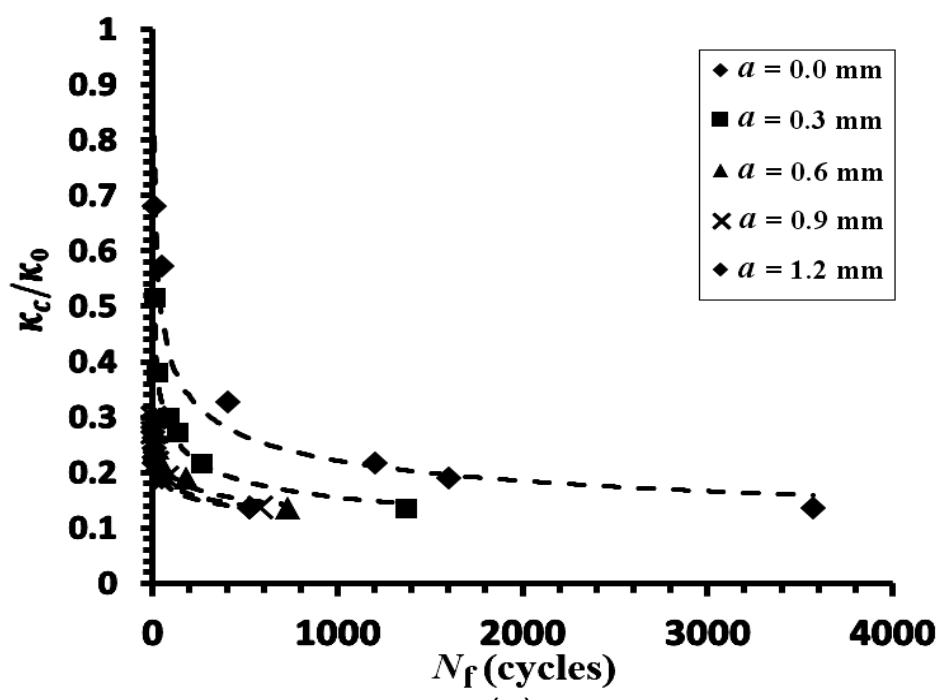

(a)

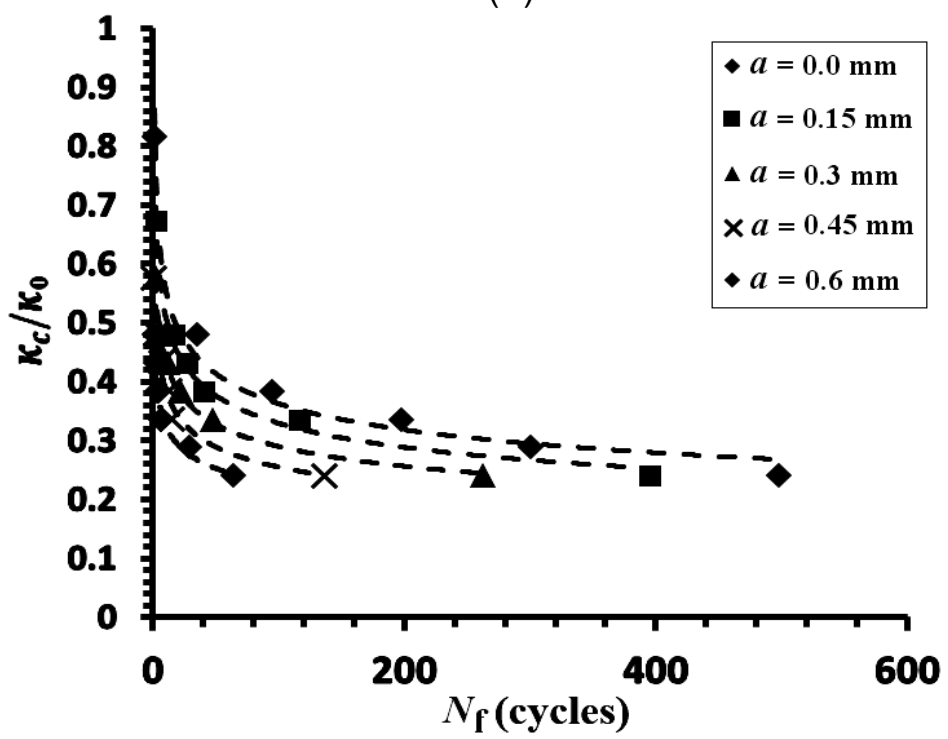

(b)

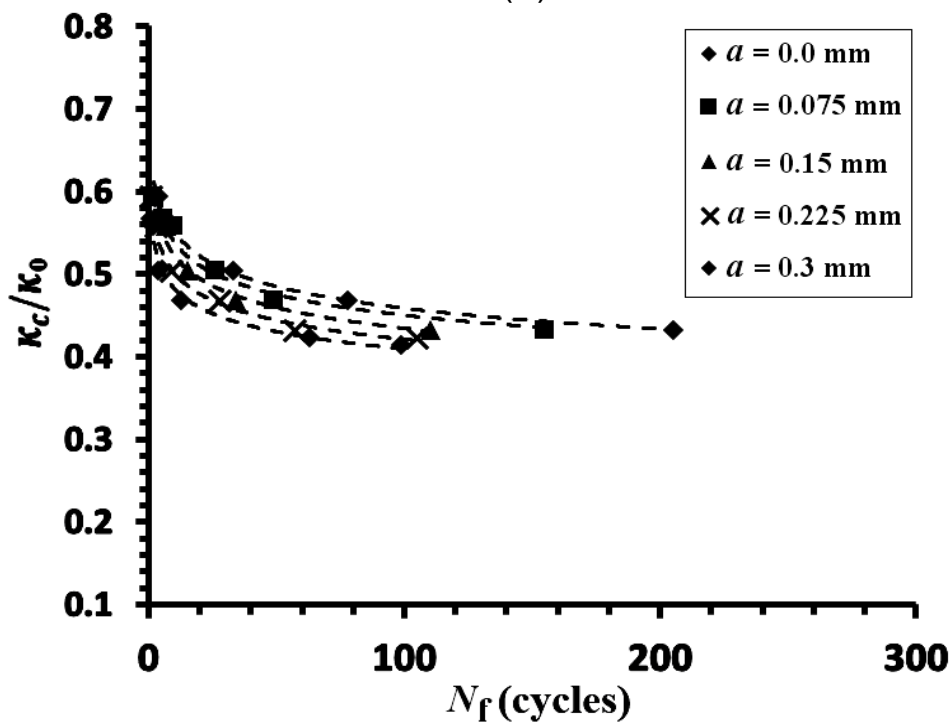

(c)

Fig. 9. Experimental controlled curvature $\left(\kappa_{\mathrm{c}} / \kappa_{\mathrm{o}}\right)$ - number of bending cycles required to produce failure $\left(N_{\mathrm{f}}\right)$ curves for local sharp-dented 6061-T6 aluminum alloy tubes with $D_{\mathrm{o}} / t=$ (a) 16.5 , (b) 31.0 and (c) 60.0 subjected to cyclic bending. 


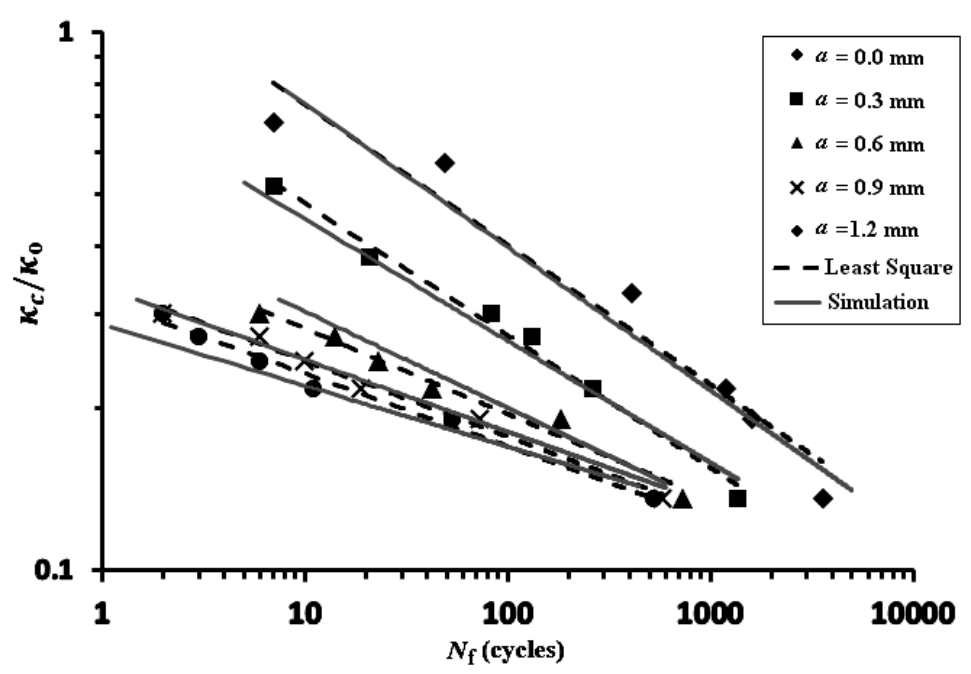

(a)

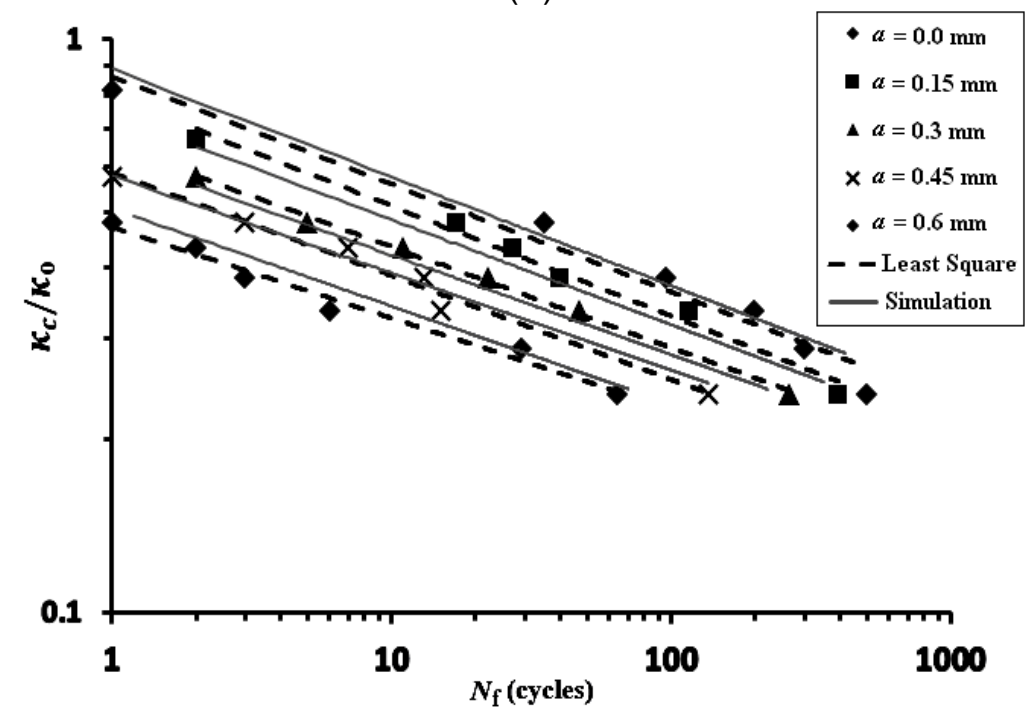

(b)

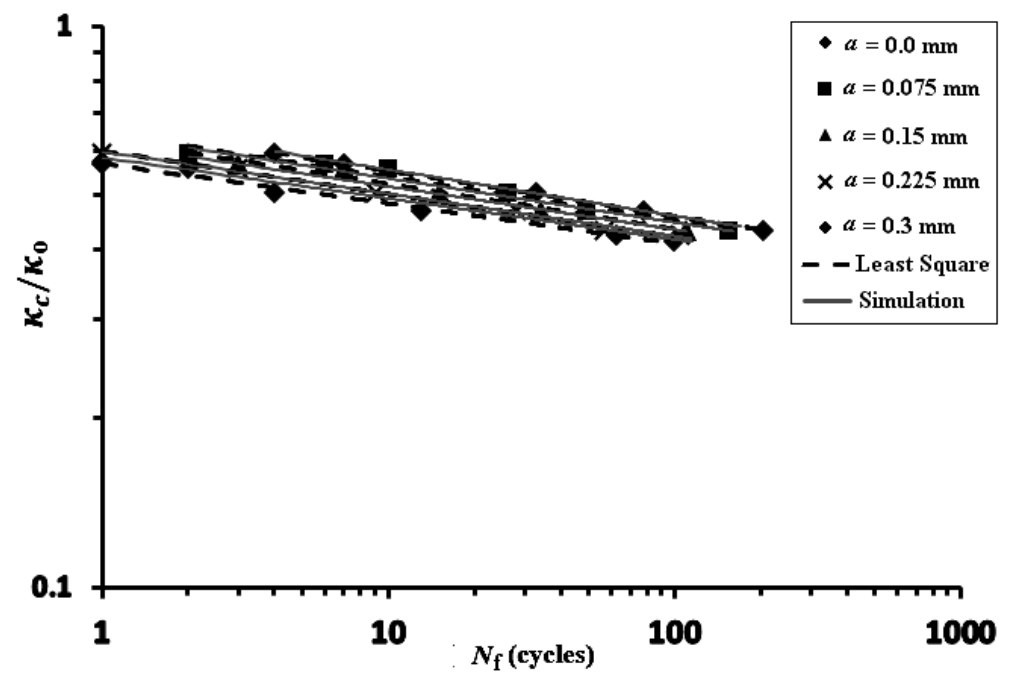

(c)

Fig.10. Experimental and simulated controlled curvature $\left(\kappa_{\mathrm{c}} / \kappa_{\mathrm{o}}\right)$ - number of bending cycles required to produce failure $\left(N_{\mathrm{f}}\right)$ curves for local sharp-dented 6061-T6 aluminum alloy tubes with $D_{\mathrm{o}} / t=$ (a) 16.5 , (b) 31.0 and (c) 60.0 subjected to cyclic bending on a log-log scale. 


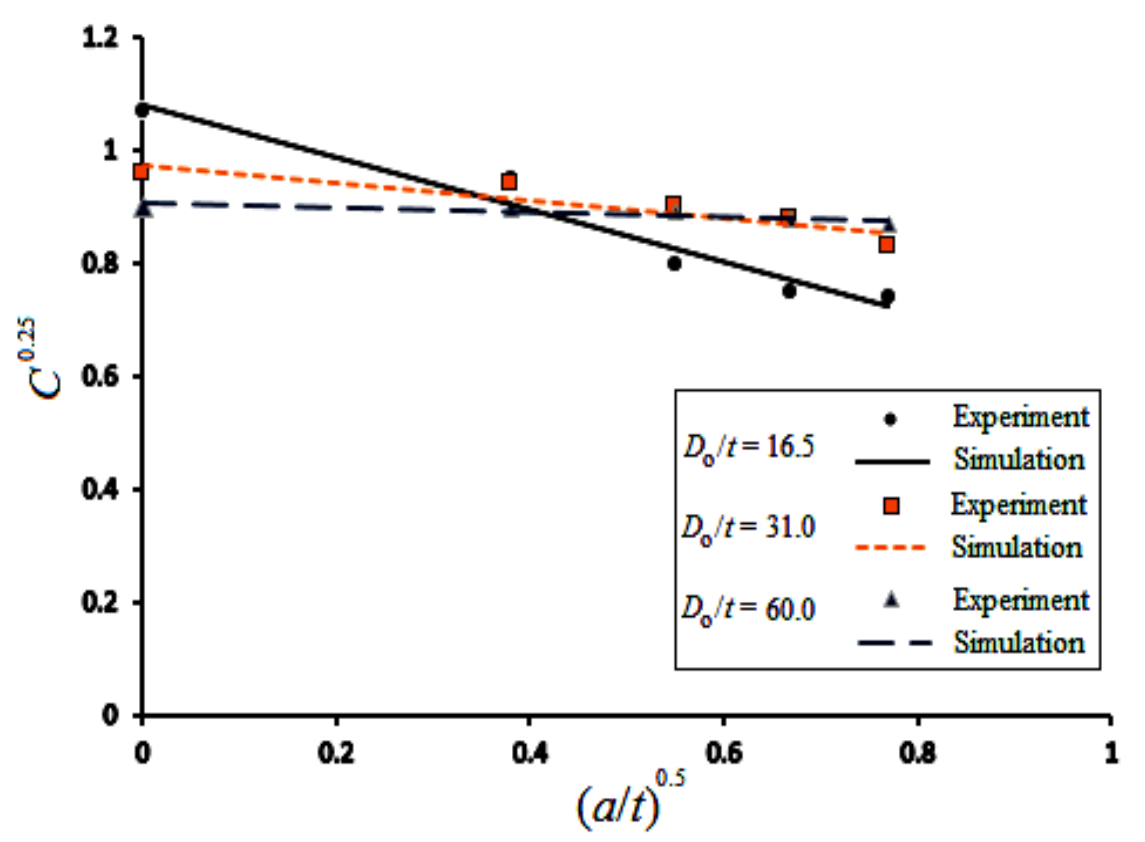

(a)

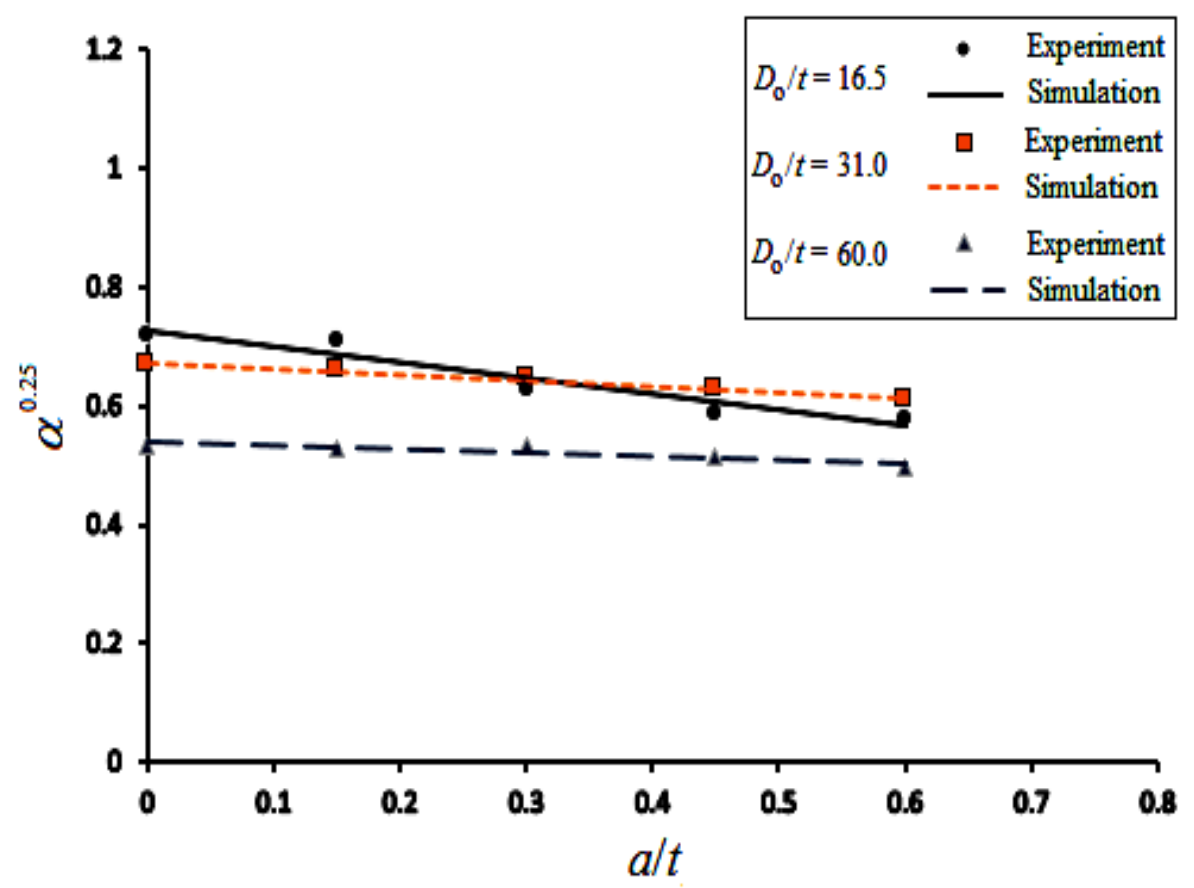

(b)

Fig.11. (a) The relationship between $C^{0.25}$ and $(a / t)^{0.5}$ for $D_{0} / t=16.5,31.0$ and 60.0 , (b) the relationship between $\alpha^{0.25}$ and $a / t$ for $D_{\mathrm{o}} / t=16.5,31.0$ and 60.0 . 


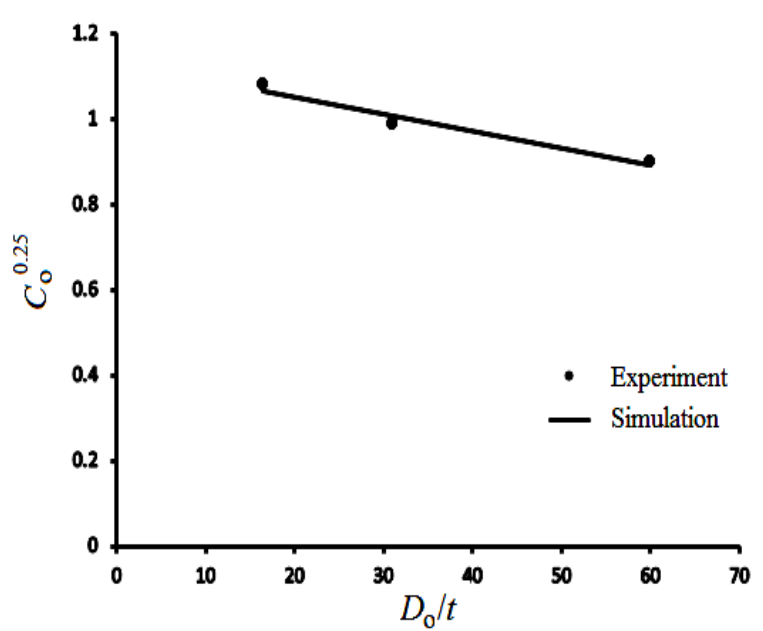

(a)

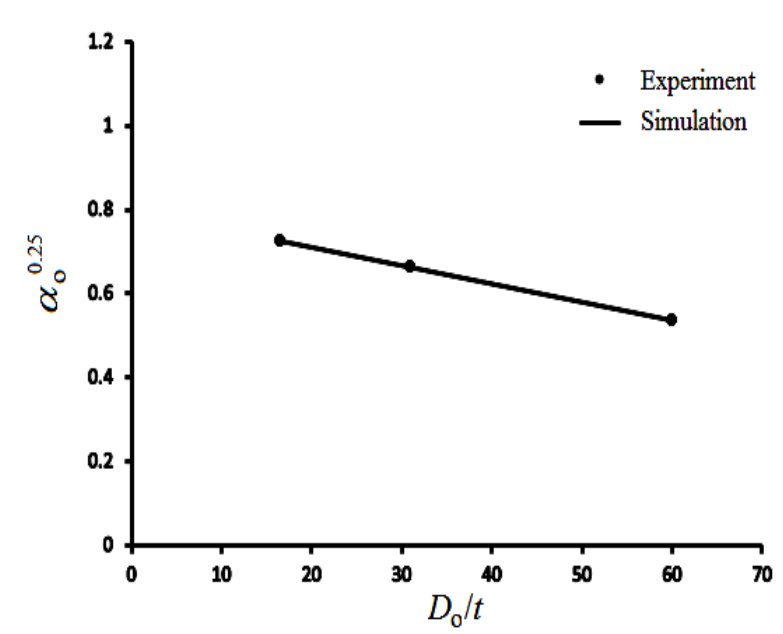

(c)

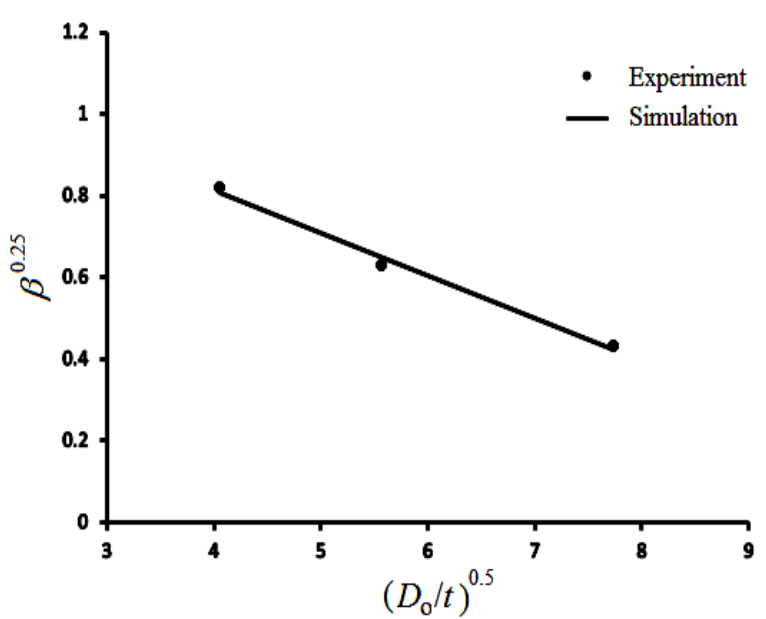

(b)

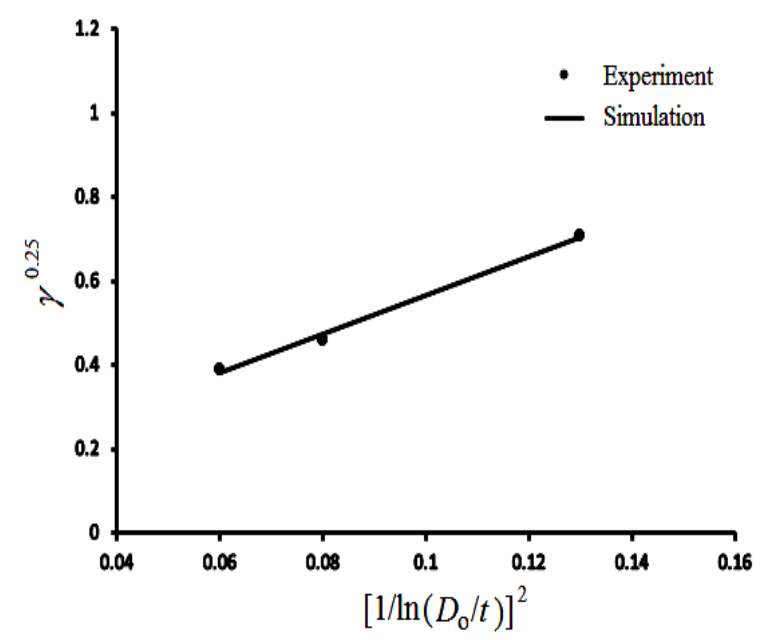

(d)

Fig.12. (a) The relationship between $C^{0.25}$ and $D_{\mathrm{o}} / t$, (b) the relationship between $\beta^{0.25}$ and $\left(D_{\mathrm{o}} / t\right)^{0.5},(\mathrm{c})$ the relationship between $\alpha_{\mathrm{o}}^{0.25}$ and $D_{\mathrm{o}} / t$, and $(\mathrm{d})$ the relationship between $\gamma^{.25}$ and $\left[1 / \ln \left(D_{\mathrm{o}} / t\right)\right]^{2}$.

Table 1. Chemical composition of 6061-T6 aluminum alloy (weight \%)

\begin{tabular}{|c|c|c|c|c|c|c|c|c|c|}
\hline $\begin{array}{c}\text { Chemical } \\
\text { Composition }\end{array}$ & Al & Mg & Si & Fe & Zn & Mn & Cr & Ti & Ni \\
\hline $\begin{array}{c}\text { Proportion } \\
(\%)\end{array}$ & 98.096 & 0.937 & 0.535 & 0.139 & 0.0983 & 0.022 & 0.022 & 0.012 & 0.005 \\
\hline
\end{tabular}

